\title{
ASSESSMENT AND MAPPING OF HEAVY METALS POLLUTION IN TEA PLANTATION SOIL OF ZHEJIANG PROVINCE BASED ON GIS
}

\author{
Lianqing Zhou ${ }^{1, *}$, Zhou Shi $^{1}$, Youwei Zhu ${ }^{2}$ \\ ${ }^{1}$ Institute of Agricultural Remote Sensing and Information Technology Application, Zhejiang \\ University, Hangzhou, Zhejiang Province, P.R. China 310029 \\ ${ }^{2}$ Protection and Monitoring Station of Agricultural Environment, Bureau of Agriculture \\ * Zhejiang Province, Hangzhou, Zhejiang Province, P.R. China 310020 \\ * Corresponding author, Address: Institute of Agricultural Remote Sensing and Information \\ Technology Application, Zhejiang University, Hangzhou, Zhejiang Province ,P.R. China \\ 310029, Tel:+86-571-86971149, Fax:+86-571-86971831,Email: lianqing@zju.edu.cn
}

Abstract: According to the 2nd grade $(\mathrm{pH}<6.5)$ of $\mathrm{GB} 1516-1995$, Inverse Distance Weighted interpolation method of GIS, single and Nemeorow's synthetic pollution indexes were used to assess and map heavy metals pollution in tea plantation soil of the primary tea producing area in 12 counties of Zhejiang Province. It was indicated by using exploring statistics and assessment map of single pollution index that contamination of $\mathrm{Cd}$ was the highest, followed by $\mathrm{Ni}, \mathrm{As}$ and $\mathrm{Zn}$, while the contaminations of $\mathrm{Cr}, \mathrm{Cu}, \mathrm{Hg}$ and $\mathrm{Pb}$ were all zero; almost all of the tea soil were unpolluted by $\mathrm{Cr}, \mathrm{Cu}, \mathrm{Hg}$ and $\mathrm{Pb}$, and few was slightly polluted by $\mathrm{As}, \mathrm{Cd}$, Ni and $\mathrm{Zn}$.Moreover, it revealed on the assessment map created from Nemeorow's synthetic pollution indexes that 160 samples were located in the safety domain, 12 samples were located in the precaution domain and only 7 samples were slightly polluted; up to $93 \%$ of the whole study area was belonged to safety domain, $6.5 \%$ was the precaution domain, whereas only $0.50 \%$ area was the slightly polluted domain.

Keywords: heavy metals pollution, tea plantation soil, assessment and mapping, GIS

Please use the following format when citing this chapter:

Zhou, L., Shi, Z. and Zhu, Y., 2009, in IFIP International Federation for Information Processing, Volume 293, Computer and Computing Technologies in Agriculture II, Volume 1, eds. D. Li, Z. Chunjiang, (Boston: Springer), pp. 69-78. 


\section{INTRODUCTION}

Zhejiang Province is one of the leading tea producing area in China with a planting area of 159,700 ha(Xu,2004; Huang,2005).The heavy metals pollution was the most important one of the primary three factors affected tea quality safety of Zhejiang Province ( $\mathrm{Yu}, 2005)$. The heavy metals contents in tea was postively correlated to the one in tea soil(Shi et al., 2003; $\mathrm{Wu}$ et al., 2002). Since a survey of soil heavy metal contents might supply some fundamental information for the environmental assessment, extensive investigations of soils had been carried out in some countries and regions in recent years (Elsokkary et al., 1995; Adamo et al., 2003) and some works also had been carried out to evaluate the heavy metal contamination in China(Li et al., 2001; Wang,2002). However,there was few detailed and systematically studies undertaken to investigate the heavy metal contents in tea plantation soil coupling GIS with single and Nemeorow's synthetic pollution indexes in China. The main objector of this inverstigation was to: (1) assess the heavy metals pollution of tea soil in Zhejiang by single and Nemeorow's synthetic pollution indexes;(2) make assement maps of heavy metals by GIS sptail interpolation and drawing technologies.

\section{MATIERIALS AND METHOD}

\subsection{Study area}

The tea producing area of Zhejiang Province were devided into three predominant domains of east,south and west of Zhejiang by the Regional layout and programming of characteristic and predominant agriculture products in Zhejiang Province(2003-2007) (Huang, 2005).12 counties were picked out as the study area of this inverstigation.

\subsection{Soil sampling and analysis}

A total of 179 soil samples were collected from tea plantation of 12 counties in Zhejiang Province(Fig.1). A Trimble Pro-XR Global Positioning System (GPS, Trimble,USA) was used to locate each sampling point to within $\pm 5 \mathrm{~m}$. Composite soil samples were taken from each of these sampling points. Using quincunx-sampling method, 5 soil cores were collected to a depth of $0.2 \mathrm{~m}$ in a $25-\mathrm{m}$ rectangle of each grid node, and then bulked to give a composite sample.

Soil samples were air-dried at $30^{\circ} \mathrm{C}$ and sieved through a $0.002-\mathrm{m}$ polyethylene sieve. After digestion with a mixed acid of aqua fortis, nitric 
acid $\left(\mathrm{HNO}_{3}\right)$, fluorin acid $(\mathrm{HF})$ and chlorine acid $\left(\mathrm{HClO}_{4}\right)$, heavy metal contents were determined according to the national standard methodologies (NSPRC, 1995). Concentrations of $\mathrm{Cd}, \mathrm{Pb}, \mathrm{Cu}, \mathrm{Cr}, \mathrm{Ni}$ and $\mathrm{Zn}$ were determined using an inductively coupled plasmamass spectrometry (ICP-MS; POEMS 3, Thermo Electron,USA).Applying atomic spectrofluorophotometer (AFS,XGY-1011A,IGGE,China) to detect the concentrations of As, Hg. Standard reference material,GSS-1 soil was obtained from the Institute of Geophysical and Geochemical Prospecting, Department of Geology and Minerals of China,was used as quality assurance measure for the analyses of total heavy metals and incorporated during the analysis.

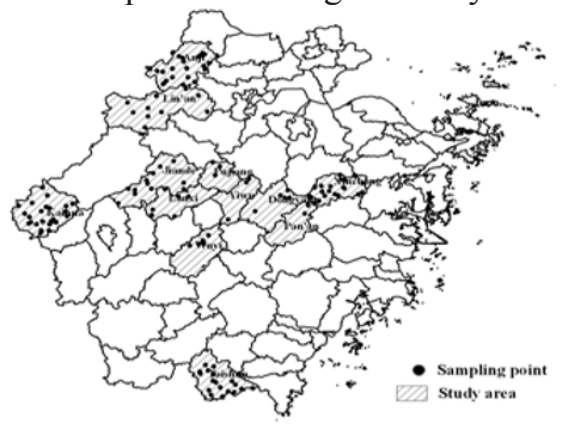

Fig. 1: Sampling points and study area

\subsection{Data analysis}

Single and Nemerow's synthetical pollution indexes were applied to assess soil environmental quality in previous study (Liu et al., 2004). In the present study, these two were utilized for the degree of soil environmental pollution and integrative assessment of soil environmental quality, the $2^{\text {nd }}$ grade $(\mathrm{pH}<6.5)$ of Standards Soil Environmental Quality (GB 15618-1995) (NSPRC,1995) was used as soil quality assessment criteria. Its equation was as follows:

$$
P_{n}=\sqrt{\left(\operatorname{Max}_{i}^{2}+\bar{P}_{i}^{2}\right) / 2}
$$

where

$$
P_{i}=C_{i} / S_{i}
$$

where, $P_{n}$ is the Nemerow's synthetical pollution index; $P_{i}$ is the single pollution index of the $i$ th heavy metal, if $P_{i}<=1$, soil is safe; if $P_{i}>1$,soil is polluted by the $i$ th heavy metal; the greater the $P_{i}$ is, the heavier the pollution is. $C_{i}$ is the measured concentration of the $i$ th heavy metal, $S_{i}$ is the required standard of the $i$ th heavy metal, $\bar{P}_{i}$ and $\operatorname{Max}_{i}$ is the average and the 
maximum value of the pollution indices of the $i$ th heavy metal.

The Nemerow's synthetical pollution index $P_{n}$ for all the soil sampling points was calculated to show the relative magnitudes of soil pollution. Higher $P_{n}$ value indicates more serious pollution. According to GB156181995, soil environmental quality was classified into 5 grades from Nemerow's synthetical pollution index, which are presented in Table 1.

Table 1. Classification criterions for polluted index of soil enviroment quality

\begin{tabular}{ccl}
\hline Grade & Synthetical index & Appraisal result \\
\hline 1 & $P_{n} \leq 0.7$ & Safety domain \\
2 & $0.7<P_{n} \leq 1.0$ & Precaution domain \\
3 & $1<P_{n} \leq 2.0$ & Slightly polluted domain \\
4 & $2<P_{n} \leq 3.0$ & Moderatey polluted domain \\
5 & $P_{n}>3.0$ & Seriously pllouted domain \\
\hline
\end{tabular}

IDW interpolation method is based on a basic principle of geography that things close to one another are more alike. IDW is used to create a continuous surface from sampled point values by Using ArcGIS Spatial Analyst(ESRI,2004) in current study, the assessment maps of single pollution index were generated from single polltion index of each of eight heavy metals in all sampled points respectively, and soil environmental quality map was generated from all sampled points with Nemerow's synthetical pollution index.

\section{RESULTS AND DISCUSSION}

\subsection{Heavy metal concentrations in tea soil}

Exploring statistics of eight heavy mentals were summarized in table 2 . Based on the $2^{\text {nd }}$ grade $(\mathrm{pH}<6.5)$ GB 1516-1995, the allowed values for these heavy metals were also listed.

Table 2. Heavy metal concentrations of tea soils in Zhejiang Province ( $\mathrm{mg} / \mathrm{kg}$ )

\begin{tabular}{lcccccccc}
\hline & $\mathrm{As}$ & $\mathrm{Cd}$ & $\mathrm{Cr}$ & $\mathrm{Hg}$ & $\mathrm{Pb}$ & $\mathrm{Zn}$ & $\mathrm{Cu}$ & $\mathrm{Ni}$ \\
\hline Range & $2.7-65.6$ & $0.06-0.47$ & $10.0-121.0$ & $0.007-0.211$ & $13-75$ & $28-516$ & $4.3-53.8$ & $4.2-56.9$ \\
Mean & 10.10 & 0.14 & 55.51 & 0.04 & 29.91 & 71.98 & 19.19 & 18.61 \\
Minimum & 2.70 & 0.06 & 10.0 & 0.01 & 13.0 & 28.0 & 4.30 & 4.20 \\
Maximum & 65.60 & 0.47 & 121.0 & 0.21 & 75.0 & 516.0 & 53.80 & 56.90 \\
Pover & 1 & 9 & 0 & 0 & 0 & 1 & 0 & 5 \\
Tover(\%) & 0.559 & 5.028 & 0 & 0 & 0 & 0.559 & 0 & 2.793 \\
Threshold & 40 & 0.30 & 150 & 0.30 & 300 & 200 & 150 & 40 \\
\hline
\end{tabular}

Pover: points abover threshold; Tover: total percentage above threshold 
As shown in the table, the average concentrations of $\mathrm{As}, \mathrm{Cd}, \mathrm{Cr}, \mathrm{Hg}, \mathrm{Pb}$, $\mathrm{Zn}, \mathrm{Cu}$ and $\mathrm{Ni}$ were all below the allowed values of GB 1516-1995. With respect to the total percentage (Tover) of above this allowed limits, contamination of $\mathrm{Cd}$ was the highest, which reached to $5.028 \%$, followed by $\mathrm{Ni}$, As and $\mathrm{Zn}$; contaminations of $\mathrm{Cr}, \mathrm{Hg}, \mathrm{Pb}$ and $\mathrm{Cu}$ were the lowest, which were all zero.

\subsection{Assessment and mapping of heavy metals pollution by single pollution index}

\subsubsection{As}

Contamination of As ranged from 2.7 to $65.6 \mathrm{mg} / \mathrm{kg}$ and mean value was $10.10 \mathrm{mg} / \mathrm{kg}$ which was lower than the threshold $(30 \mathrm{mg} / \mathrm{kg})$. There was only 1 sample which single pollution index of As was a little greater than 1.0.It was to say that this sample was polluted by As.

A spatial distribution map of As contamination in study area was shown as Fig.2.It revealed that almost all of the tea soil in study area was absolutely safe and only few was slightly polluted by As.

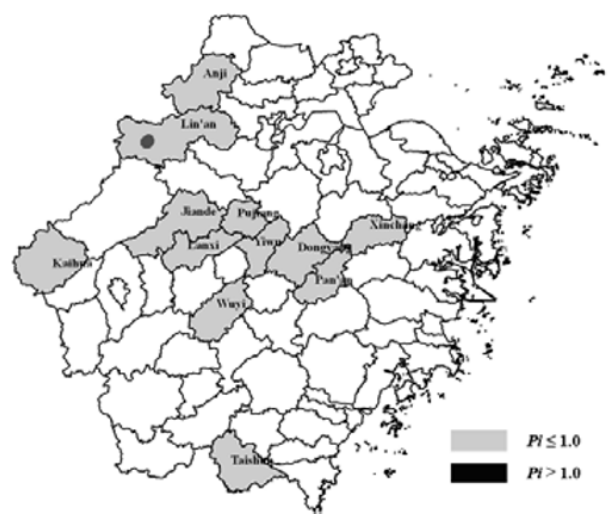

Fig.2: Spatial distribution map of As

\subsubsection{Cd}

Contamination of Cd ranged from 0.06 to $0.47 \mathrm{mg} / \mathrm{kg}$ and mean value was $0.14 \mathrm{mg} / \mathrm{kg}$ which was lower than the threshold $(0.60 \mathrm{mg} / \mathrm{kg})$. There was 9 samples which single pollution index were greater than 1.0. It was to say that there was $5.028 \%$ of soil samples polluted by $\mathrm{Cd}$. 
A spatial distribution map of Cd contamination in study area was shown as Fig.3.It revealed that most of the tea soil in study area was safe and only few was slightly polluted by $\mathrm{Cd}$.

\subsubsection{Zn}

Contamination of $\mathrm{Zn}$ ranged from 28 to $516 \mathrm{mg} / \mathrm{kg}$ and mean value was $71.98 \mathrm{mg} / \mathrm{kg}$ which was lower than the threshold $(250 \mathrm{mg} / \mathrm{kg})$. There was only 1 sample which single pollution index was greater than 1.0.It was to say that there was only $0.559 \%$ of soil samples polluted by $\mathrm{Zn}$.

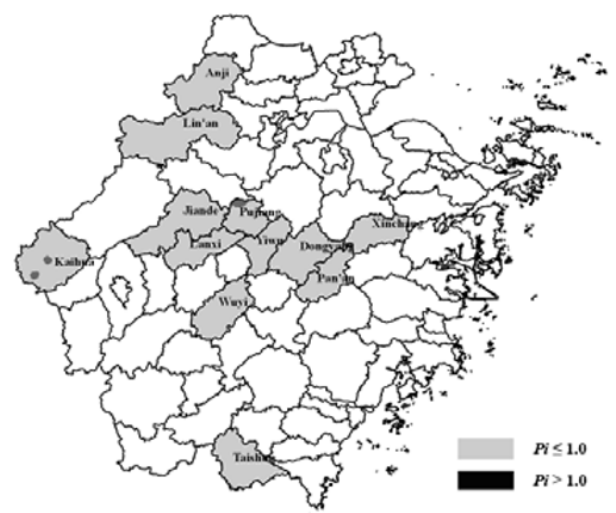

Fig.3: Spatial distribution map of Cd

A spatial distribution map of $\mathrm{Zn}$ contamination in study was shown as Fig.4. It revealed that most of the tea soil in study area was safe and only few was slightly polluted by $\mathrm{Zn}$.

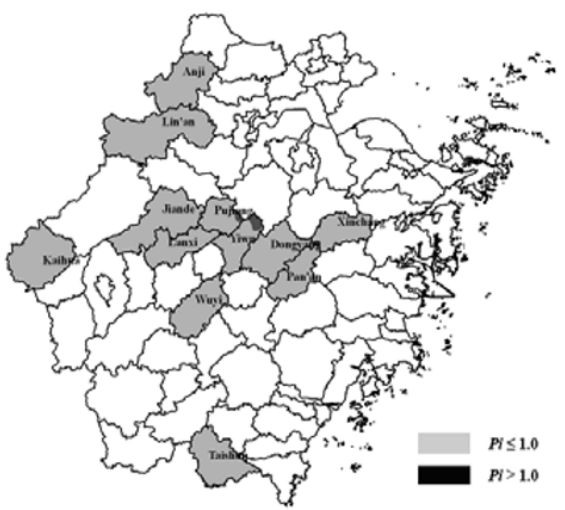

Fig.4: Spatial distribution map of Zn 


\subsubsection{Ni}

Contamination of Ni ranged from 4.2 to $56.9 \mathrm{mg} / \mathrm{kg}$ and mean value of $\mathrm{Ni}$ was $18.61 \mathrm{mg} / \mathrm{kg}$ which was lower than the threshold $(50 \mathrm{mg} / \mathrm{kg}$ ). There was 5 samples which single pollution index were greater than 1.0.It was to say that there was $2.793 \%$ of soil samples polluted by $\mathrm{Ni}$.

A spatial distribution map of Ni Contamination in study area was shown as Fig.5.It revealedthat most of the tea soil in study area was safe and not polluted and only few was slightly polluted by Ni.

\subsection{5 $\mathrm{Cr}, \mathrm{Hg}, \mathrm{Pb}, \mathrm{Cu}$}

Contamination of $\mathrm{Cr}$ ranged from 10.0 to $121.0 \mathrm{mg} / \mathrm{kg}$ and mean value of Cr was $55.51 \mathrm{mg} / \mathrm{kg}$ which was lower than the threshold $(200 \mathrm{mg} / \mathrm{kg}$ ), contamination of $\mathrm{Hg}$ ranged from 0.007 to $0.211 \mathrm{mg} / \mathrm{kg}$ and mean value was $0.04 \mathrm{mg} / \mathrm{kg}$ which was lower than the threshold $(0.50 \mathrm{mg} / \mathrm{kg})$, contamination of $\mathrm{Pb}$ ranged from 13 to $75 \mathrm{mg} / \mathrm{kg}$ and mean value of $\mathrm{Pb}$ was $29.91 \mathrm{mg} / \mathrm{kg}$ which was lower than the threshold $(300 \mathrm{mg} / \mathrm{kg})$, contamination of $\mathrm{Cu}$ ranged from 4.3 to $53.8 \mathrm{mg} / \mathrm{kg}$ and mean value of $\mathrm{Cu}$ was $19.19 \mathrm{mg} / \mathrm{kg}$ which was lower than the threshold $(100 \mathrm{mg} / \mathrm{kg})$.

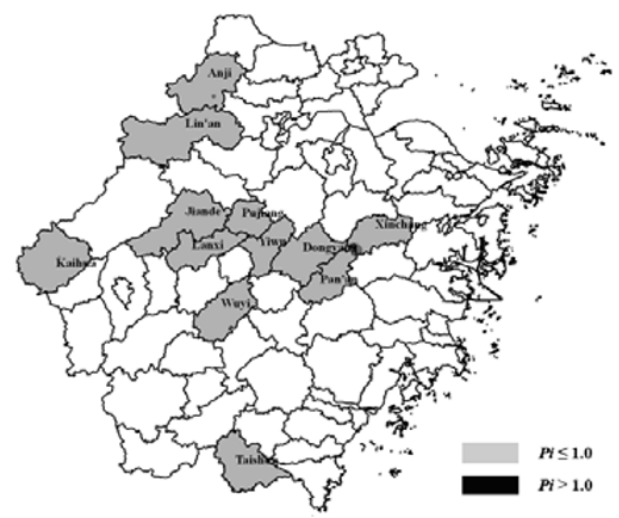

Fig.5: Spatial distribution map of $\mathrm{Ni}$

There exist no sample which single pollution index of $\mathrm{Cr}, \mathrm{Hg}, \mathrm{Pb}$ or $\mathrm{Cu}$ was greater than 1.0.It was to say that all of soil samples were unpolluted by $\mathrm{Cr}, \mathrm{Hg}, \mathrm{Pb}$ or $\mathrm{Cu}$.

The spatial distribution maps of $\mathrm{Cr}, \mathrm{Hg}, \mathrm{Pb}$ and $\mathrm{Cu}$ contamination in study area was shown as Fig.6. It revealed by all maps that all of the tea soil in study area was safe from $\mathrm{Cr}, \mathrm{Hg}, \mathrm{Pb}$ and $\mathrm{Cu}$. 


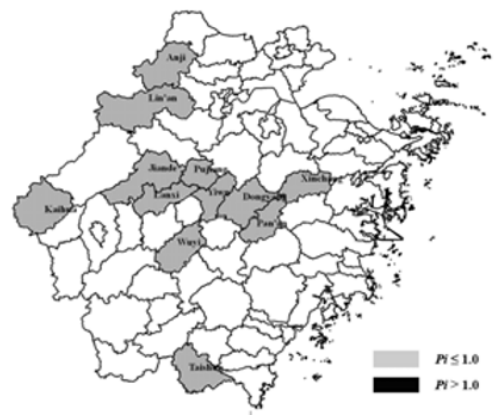

$\mathrm{Cr}$

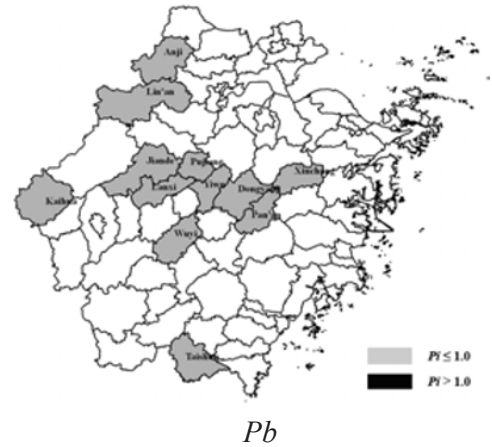

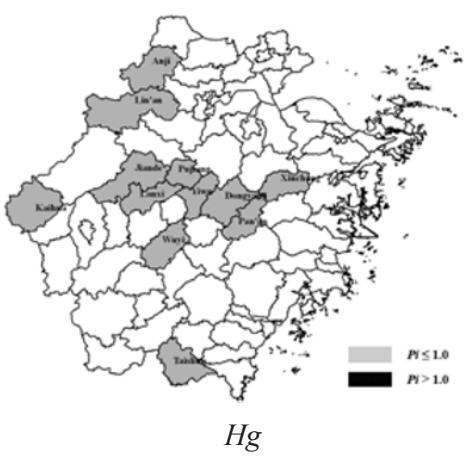

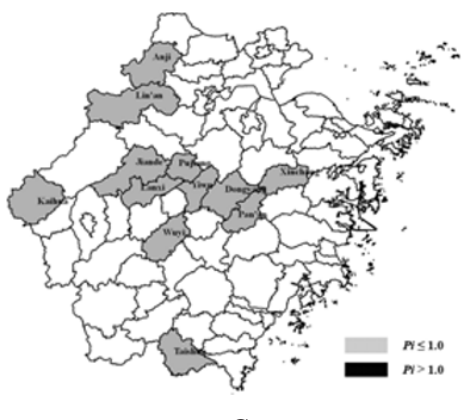

$\mathrm{Cu}$

Fig.6: Spatial distribution map of $\mathrm{Cr}, \mathrm{Hg}, \mathrm{Pb}, \mathrm{Cu}$

\subsection{Assessment and mapping of heavy metals pollution by Nemeorow synthetic pollution index}

The assessment map of heavy metals pollution in study area was illustrated in Fig.7, which created from the Nemerow's synthetical pollution index of all tea soil sampling points .

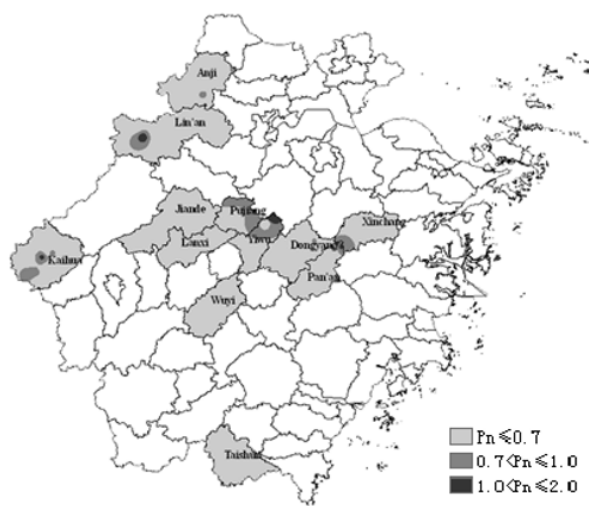

Fig. 7: Assessment map of tea soil environmental quality of Zhejiang Province 
It should be noticed that the interpolated surface were only generated in 12 counties where soil sampling points were collected. As shown in Fig.7, up to $93 \%$ of the whole study area belonged to the safety domain, $6.5 \%$ belonged to the precaution domain, whereas only $0.50 \%$ area was slightly polluted domain.Summarized with the whole 179 samples, 160 samples were in the safety domain in which the soils were considered as unpolluted,12 samples were located in the precaution domain in which heavy metals were accumulated in agricultural soils but below the allowed limits and only 7 samples were slightly polluted, respectively. In other words, almost all of tea soil in study area was not contaminated with these heavy metals.

\section{CONCLUSIONS}

According to the $2^{\text {nd }}$ grade $(\mathrm{pH}<6.5)$ of GB1516-1995, IDW interpolation method of GIS, single and Nemeorow synthetic pollution indexes were used to assess and map heavy metals pollution in tea soil of primary tea producing area in 12 counties of Zhejiang Province.

By using exploring statistics and assessment map of single pollution index of eight heavy mentals, with respect to the total percentage of above the allowed limits, contamination of Cd was the highest, which reached 5.028\%, followed by $\mathrm{Ni}, \mathrm{As}$ and $\mathrm{Zn}$, contaminations of $\mathrm{Cr}, \mathrm{Hg}, \mathrm{Pb}$ and $\mathrm{Cu}$ were all zero. Almost all of the tea soil of study area was safe and unpolluted by $\mathrm{Cr}$, $\mathrm{Cu}, \mathrm{Hg}$ and $\mathrm{Pb}$ and few was slightly polluted by $\mathrm{As}, \mathrm{Cd}, \mathrm{Zn}$ and $\mathrm{Ni}$.

By utilizing the Nemerow's synthetical pollution index, coupled with IDW, the tea soil environmental quality of 12 counties of Zhejiang Province was assessed. It revealed that 160 samples were in the safety domain, 12 samples in the precaution domain and only 7 samples were slightly polluted. According to the assessment map of tea soil environmental quality, up to $93 \%$ of the study area was belonged to safety domain, $6.5 \%$ belonged to the precaution domain, whereas only $0.50 \%$ area was slightly polluted domain.

\section{ACKNOWLEDGEMENTS}

This study had been funded by the Research Project of Zhejiang Province Ministry of Education (20070228) and the National Key Technologies R\&D Program of China (2006-BAD10A09-04). 


\section{REFERENCES}

ESRI. ArcGIS 9: Using ArcGIS Spatial Analyst. California USA: 2004,3-107

Huang Wu. Review and Expectation of Tea Industury in Zhejiang Province. China Tea Processing,2005,1:8-9(in Chinese)

I. H. Elsokkary,M. A. Amer, E. A. Shalaby. Assessment of Inorganic Lead Species and Total Organo-alkyllead in Some Egyptian Agricultural Soils. Environmental Pollution.1995,87: 225-233

Liu Hongying, Xie Z R, Chen D Y. Primary Assessment of Environmental Quality of Soils in Chengdou Area. ACTA Science Circumstance, 24(2): 2004,24:298-303.

NSPRC (National Standards of the People's Republic of China),1995.Standards for Soil Environmental Quality. GB1568-1995.

Q. Abollino,M.Aceto, M. Malandrino,C.Sarzaninia,F. Petrella. Heavy Metals in Agricultural Soils from Piedmont, Italy. Distribution, Speciation and Chemometric Data Treatment. Chemosphere, 2002,49:545-557

Shi Yuanzi,Ma Lifeng,Hang Wenyang,Ruang Jianyu. Study on the Status of Lead Content in Tea Gardens of Zhejiang Province. Journal of Tea Science,2003,23:163-166(in Chinese)

Wang Haiyang. Assessment and prediction of overall environmental quality of Zhuzhou City, Hunan Province, China. Journal of Environmental Management,2002, 66: 329-340

$\mathrm{Wu}$ Yonggang,Jiang Zhilin,Luo Qiang. The accumulation and distribution of heavy metals in teas on both sides of highway. Journal of Nanjing Forestry Unversity(Natural Science),2002,26:39-42(in Chinese)

Xu Xiaoyi. Analysis On The International Competitiveness of The Tea Industry in Zhejiang Province. Chinese Journal of Agricultural Resources and Regional Planning,2004,25:3134(in Chinese)

Yu Liaoyuan. Superficial Analysis on Quality Safety Status and Supervising Ways of Tea in Zhejiang Province.China Tea, 2005,2:16-17(in Chinese)

Zhang Mingkui, Ke Zhenxia. Heavy Metals, Phosphorus and Some Other Elements in Urban Soils of Hangzhou City,China. Pedosphere,2004,14:177-185 